\title{
Systematic review and meta-analysis of psychological intervention on patients with coronary heart disease
}

\author{
Yanmei Zhang ${ }^{1}$, Yuan Liang ${ }^{1}$, Haixia Huang ${ }^{1}$, Yulan $\mathrm{Xu}^{2}$ \\ ${ }^{1}$ Department of Cardiology, Union Hospital, Tongji Medical College, Huazhong University of Science and Technology, Wuhan, China; ${ }^{2}$ Department \\ of Nursing, Union Hospital, Tongji Medical College, Huazhong University of Science and Technology, Wuhan, China \\ Contributions: (I) Conception and design: Y Zhang; (II) Administrative support: Y Zhang; (III) Provision of study materials or patients: Y Zhang, Y \\ Liang; (IV) Collection and assembly of data: Y Xu; (V) Data analysis and interpretation: H Huang; (VI) Manuscript writing: All authors; (VII) Final \\ approval of manuscript: All authors. \\ Correspondence to: Yulan Xu. Department of Nursing, Union Hospital, Tongji Medical College, Huazhong University of Science and Technology, \\ Wuhan 430022, China. Email: xhxnkzym@163.com.
}

\begin{abstract}
Background Coronary heart disease is both a physical and mental disease, so psychological intervention can be used as part of a general cardiac rehabilitation plan. This study aimed to evaluate the effect of psychological intervention on the negative psychology of patients with coronary heart disease.

Methods: Multiple databases like PubMed, Embase, Web of Science, and Cochrane Library were used to search for the relevant studies, and full-text articles involved in the evaluation of psychological intervention versus usual care for patients with coronary heart disease. Review Manager 5.4 (The Cochrane Collaboration, Software Update, Oxford, 2020) was adopted to estimate the effects of the results among selected articles. Forest plots, sensitivity analysis, and bias analysis were also performed on the included articles.

Results: There were 17 studies that eventually met the final inclusion criteria. There were significant differences in anxiety level [mean difference (MD) $-4.53 ; 95 \%$ confidence interval (CI), -6.36 to -2.7 ; $\mathrm{P}<0.00001 ; \mathrm{I}^{2}=96 \%$ ], depression level (MD-3.43; 95\% CI, -4.85 to $-2.01 ; \mathrm{P}<0.00001 ; \mathrm{I}^{2}=96 \%$ ), and stress level (MD $-4.19 ; 95 \% \mathrm{CI},-6.86$ to $-1.52 ; \mathrm{P}<0.00001 ; \mathrm{I}^{2}=94 \%$ ), but no difference was found for total mortality $(\mathrm{P}=0.50)$.

Conclusions: This study indicated that psychological intervention has important health benefits for patients with coronary heart disease and can effectively reduce negative psychological effects such as depression, anxiety, and stress. However, the results need to be further confirmed due to the limitations.
\end{abstract}

Keywords: Psychological intervention; usual care; coronary heart disease; meta-analysis

Submitted May 25, 2021. Accepted for publication Jul 02, 2021.

doi: 10.21037/apm-21-1623

View this article at: https://dx.doi.org/10.21037/apm-21-1623

\section{Introduction}

Coronary heart disease is a cardiovascular disease with a high incidence rate in clinic. The prevalence of coronary heart disease continues to rise, especially in the elderly, the prevalence over 60 years old is more than $30 \%$. The symptoms of coronary heart disease mainly depend on the degree of ischemia involving the heart (1). Plaque composed of cholesterol and other deposits accumulate in the coronary artery wall, which can lead to coronary artery stenosis or occlusion, and then lead to coronary heart disease. Generally, when the diameter of coronary artery stenosis is more than $75 \%$, angina pectoris, arrhythmia, and even sudden death can occur (2). It seriously threatens the physical and mental health of patients, and reduces their quality of life (3).

At present, coronary heart disease is recognized as a psychosomatic disease, bad emotional stimulation can cause anxiety, tension, fear and other emotional changes in patients, thus affecting the conduction velocity of the 
heart, and then lead to coronary heart disease, social and psychological factors play an important role in its occurrence, development, rehabilitation, and prognosis $(4,5)$. It has been reported that $55.3 \%$ of patients with coronary heart disease have different degrees of negative psychology. For example, anxiety and depression are important factors affecting the occurrence, development, treatment, and rehabilitation of coronary heart disease (6). Therefore, in addition to physical therapy, psychological intervention should be given to eliminate negative psychology and to help patients increase confidence to overcome the disease, so they can recover as soon as possible $(7,8)$.

From Menninger's research on the relationship between mental state and physiology to Friedman's attempt to identify the individual characteristics of diseases by analyzing the relationship between psychological attributes and physical diseases, the relationship between psychology and physiology is a field that scientists throughout the 20 th century have been trying to better understand (9-11). Huffman et al. proposed that positive psychological intervention exercises may have a positive impact on the prognosis of patients with coronary heart disease (12).

Randomized controlled trials of psychological intervention for patients with coronary heart disease have been conducted all over the world (13-15). However, due to the limitations of sample size, region, and research object, the conclusions of single studies require verification and cannot be used to form the basis of evidence for guiding clinical practice. In short, the effect of psychological intervention on improving anxiety and depression in patients with coronary heart disease remains unclear.

In order to clarify the negative emotional impact of psychological interventions on patients with coronary heart disease, we collected relevant research reports and conducted meta-analysis for the purpose of increasing the sample size, improving test efficiency, and providing evidence-based guidance for clinical practice. We present the following article in accordance with the PRISMA reporting checklist (available at https://dx.doi.org/10.21037/ apm-21-1623).

\section{Methods}

\section{Literature search strategy}

Electronic databases including PubMed, Embase, Web of Science, and Cochrane Library were systematically searched for eligible studies from January 2000 to April 2021. The following keywords were used: (I) psychological intervention, (II) usual care, (III) coronary heart disease. These keywords were used in combination with the Boolean operator "AND" to search the literature. No restrictions on the publication language were set in the literature retrieval. In order to maximize the specificity and sensitivity of the search, the references of retrieved articles were also searched.

\section{Study selection}

Potentially relevant articles were reviewed in full to ensure that all of the following inclusion criteria were satisfied:

(I) Research compared patients receiving psychological intervention and usual care;

(II) Patients had coronary heart disease or coronary artery disease;

(III) Articles contained indicators evaluating psychologically relevant effects between psychological intervention and usual care;

(IV) Psychological intervention had at least two core components: psychological and social support. Psychological factors included cognitive behavioral therapy, psychotherapy, counseling, supportive therapy or motivational interviewing, and social support factors included social skills training to develop social networks or minimize social isolation or conflict (family/work).

(V) Full text of articles was available in English.

Studies were excluded based on the following exclusion criteria:

(I) Research focused on other diseases;

(II) Comparisons were made between other interventions;

(III) Available data were lacking, and;

(IV) Articles were classified as a review, abstract, or duplicate publication.

\section{Data extraction and quality assessment}

Teams of 2 reviewers independently screened all titles and abstracts identified by the literature search, obtained fulltext articles of all potentially eligible studies, and evaluated them for eligibility. The following data from each eligible study were extracted: first author's name, patient's age and gender, country of origin, year of publication, sample size, study duration, time of follow-up, and primary outcome. The overall methodological quality was evaluated as moderate by the Cochrane bias risk assessment tool. 


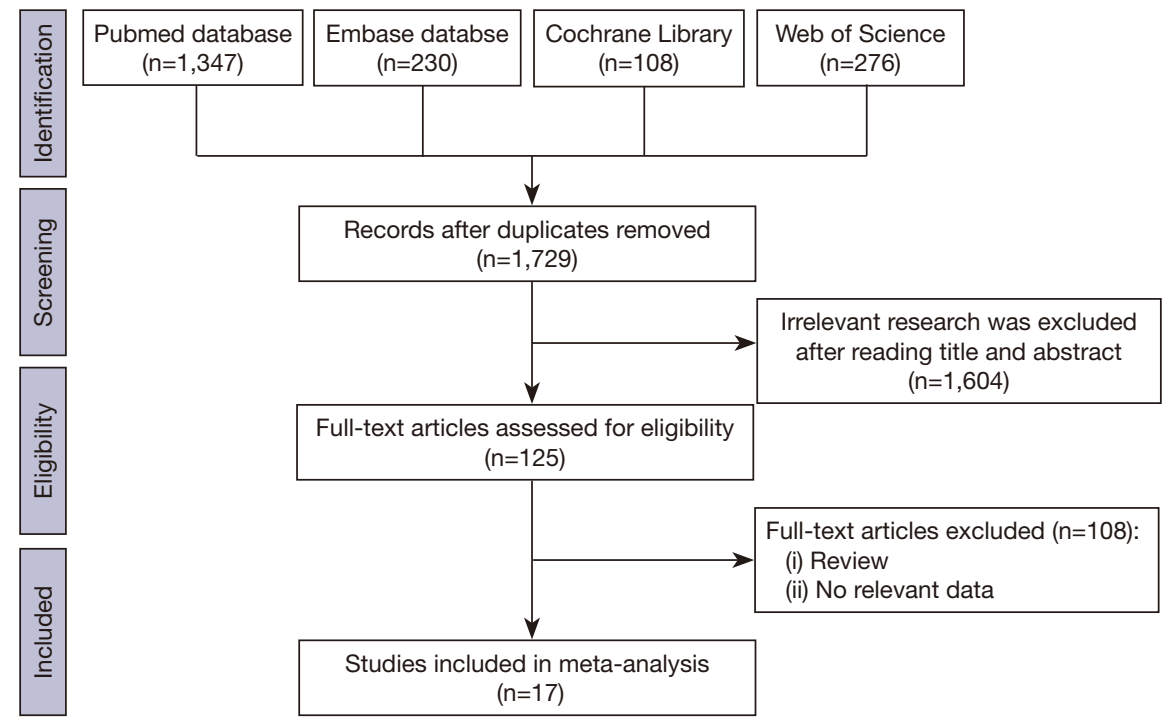

Figure 1 Flow chart of the study selection process.

\section{Statistical analysis}

Meta-analysis was performed with Review Manager 5.4 (The Cochrane Collaboration, Software Update, Oxford, 2020). Mean difference (MD) was used for measurement data, risk ratio (RR) was used for classification data, and $95 \%$ confidence interval (CI) was used for both types of indicators. Chi-square tests and $\mathrm{I}^{2}$ statistics were used to test the heterogeneity. If $\mathrm{I}^{2}<50 \%$ and $\mathrm{P}<0.05$, the homogeneity of the included literature was considered to be good, and the fixed effect model would be used; if $\mathrm{I}^{2}>50 \%$ or $\mathrm{P} \geq 0.05$, heterogeneity was considered to exist between the studies, a random effects model would be used, with sensitivity analysis being conducted to evaluate the robustness of the results. Funnel plot and Egger rank correlation were used to identify any publication bias.

\section{Results}

\section{Search process}

The electronic searches provided a total of 1,729 citations after the removal of 232 duplicate records. After a careful reading of these articles, 1,604 studies were excluded because they did not meet the inclusion criteria. With consideration to the study design and insufficient data presented, 108 articles were rejected. Finally, 17 papers were selected for analysis (16-32). The literature search process, the inclusion and exclusion criteria, and the final sample size are illustrated in Figure 1.

\section{Characteristics of included studies}

Table 1 summarizes the characteristics of the 17 studies included in the meta-analysis. The years of publication were between 2003 and 2017. These studies contained a total of 4,198 patients $(2,107$ of whom received psychological intervention and 2,091 of whom received usual care). The primary outcomes consisted of the rate of total mortality, and scores for anxiety, depression, and stress.

\section{Results of quality assessment}

Risk of bias assessment was performed at the study level, and a methodological quality assessment was performed using the Cochrane bias risk assessment tool. Only 2 studies showed selection bias, 2 studies showed performance bias, and 2 showed reporting bias. In terms of the bias summary, there was no high risk in detection bias, attrition bias, or other biases (Figure 2). Figure 3 presents a summary of the risk of bias for each included study.

\section{Results of heterogeneity test}

A total of 10 studies, comprising 379 intervention groups and 376 control groups, were found that reported anxiety scores. To analyze the differences in anxiety scores between these 2 groups, a meta-analysis was performed to calculate the overall MD using a random effects model in patients with coronary heart disease based on heterogeneity analysis. 


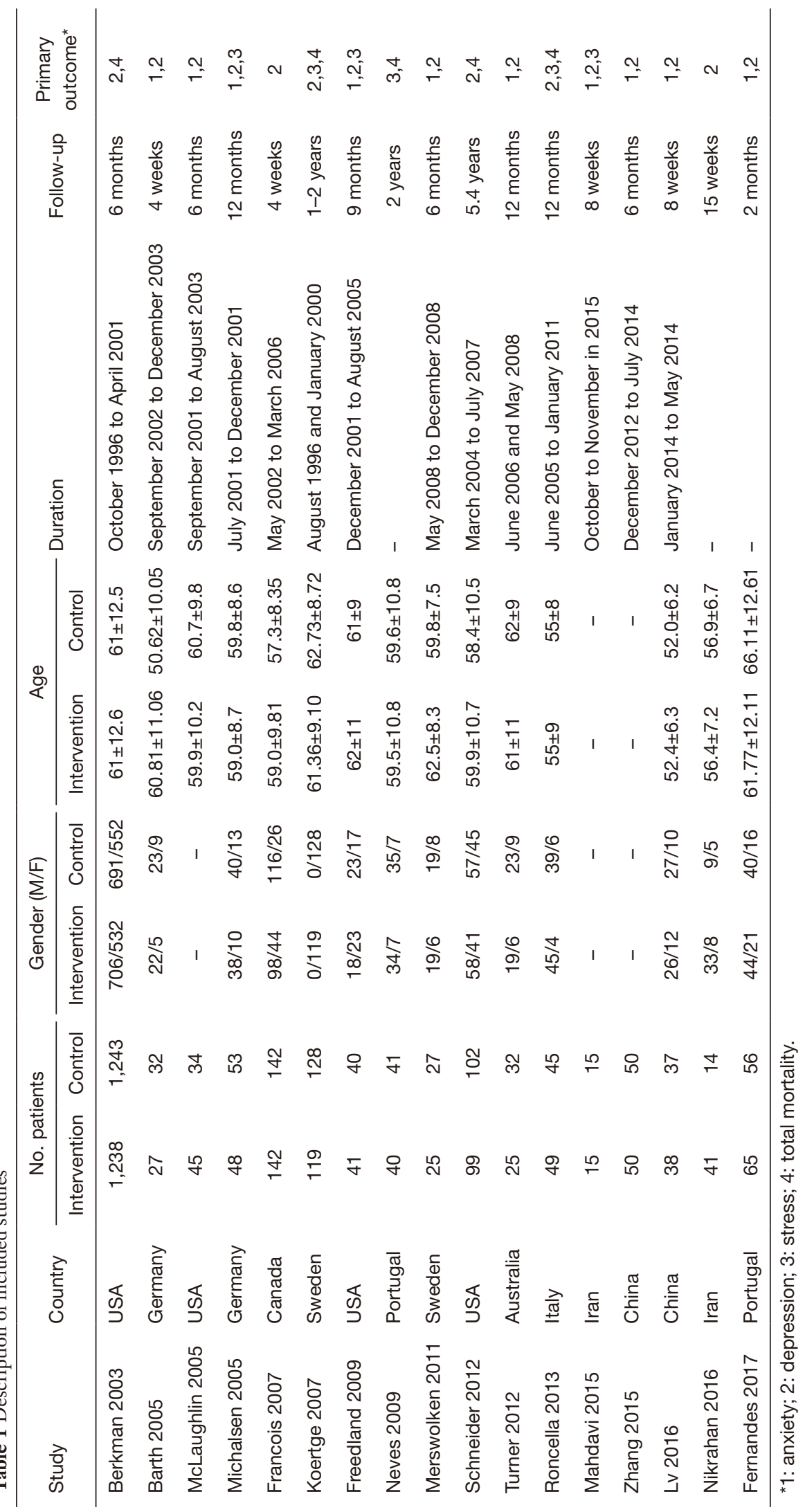




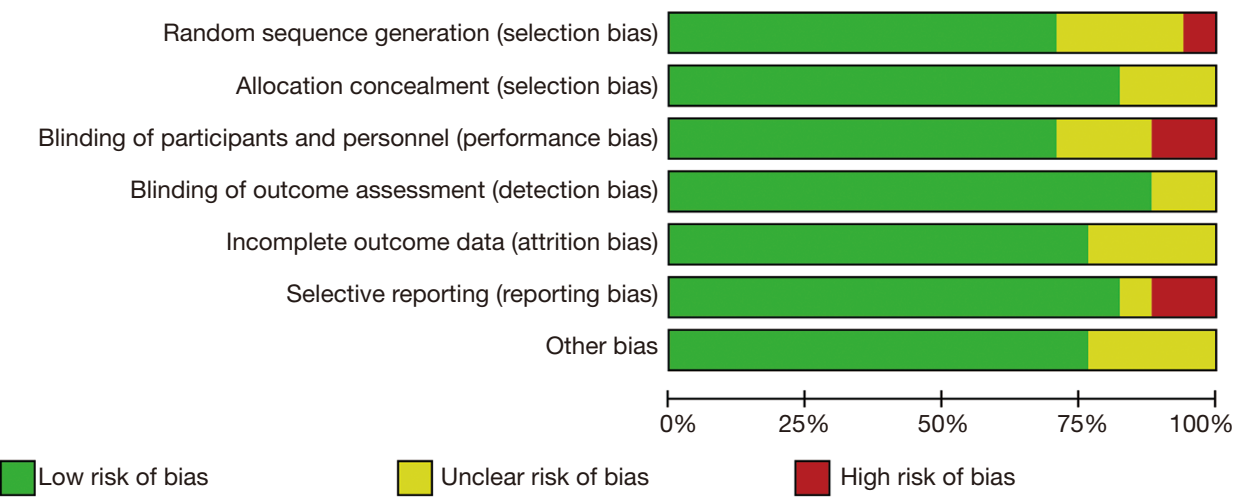

Figure 2 Assessment of the quality of the included studies: low risk of bias (green), unclear risk of bias (yellow), and high risk of bias (red).

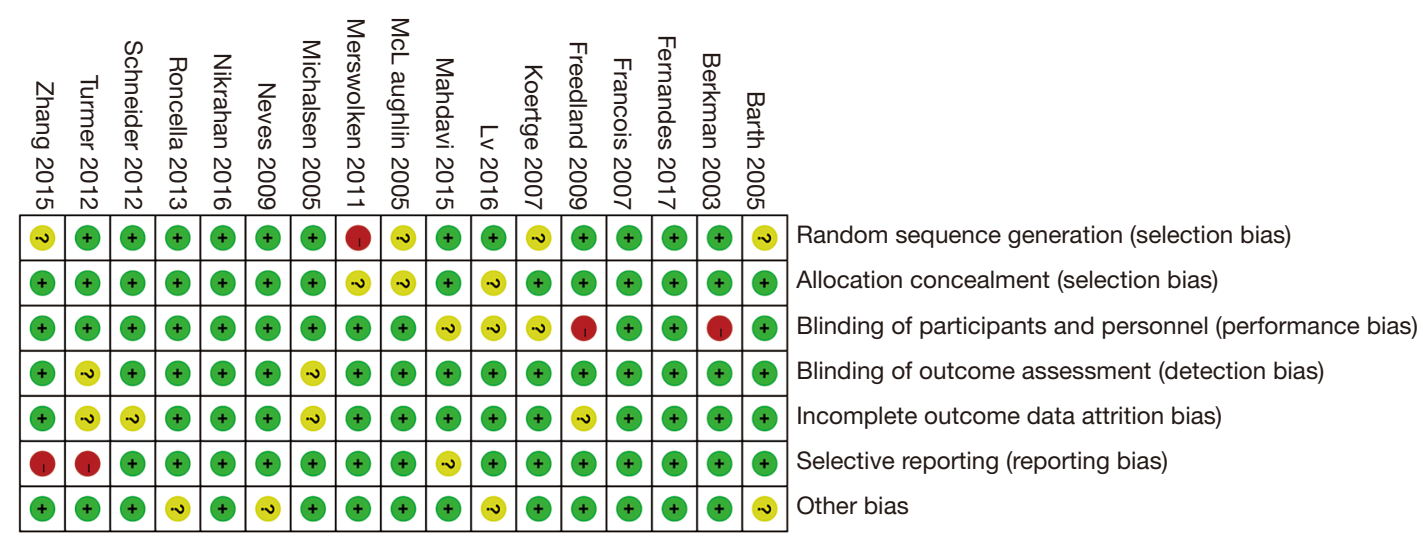

Figure 3 Risk of bias summary of each included study.

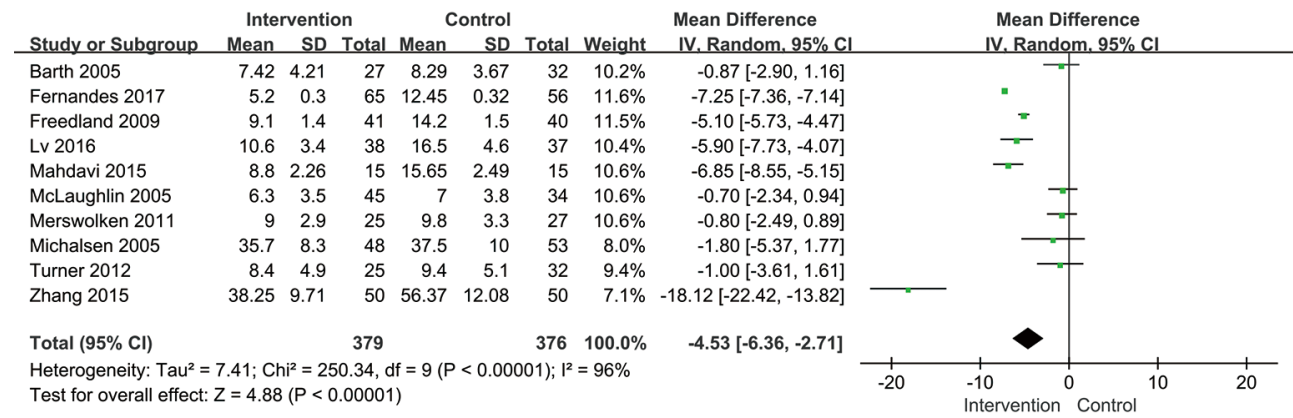

Figure 4 Forest plot showing the mean difference of anxiety scores between psychological intervention versus usual care.

The MD was -4.53 (95\% CI, -6.36 to $-2.71 ; \mathrm{P}<0.00001)$, and there was significant heterogeneity $\left(\mathrm{P}<0.00001 ; \mathrm{I}^{2}=96 \%\right.$; Figure 4).

All but 1 included study reported a depression score. A random effects model was used to evaluate the heterogeneity of the depression scores, as there was significant heterogeneity among the included studies $(\mathrm{P}<0.00001$, $\mathrm{I}^{2}=94 \%$ ) (Figure 5). The results showed that the intervention group had a significantly lower level of depression than did the control group ( $M D=-3.43 ; 95 \% \mathrm{CI},-4.85$ to -2.01 ; $\mathrm{P}<0.00001)$.

In the evaluation of differences in stress scores between 


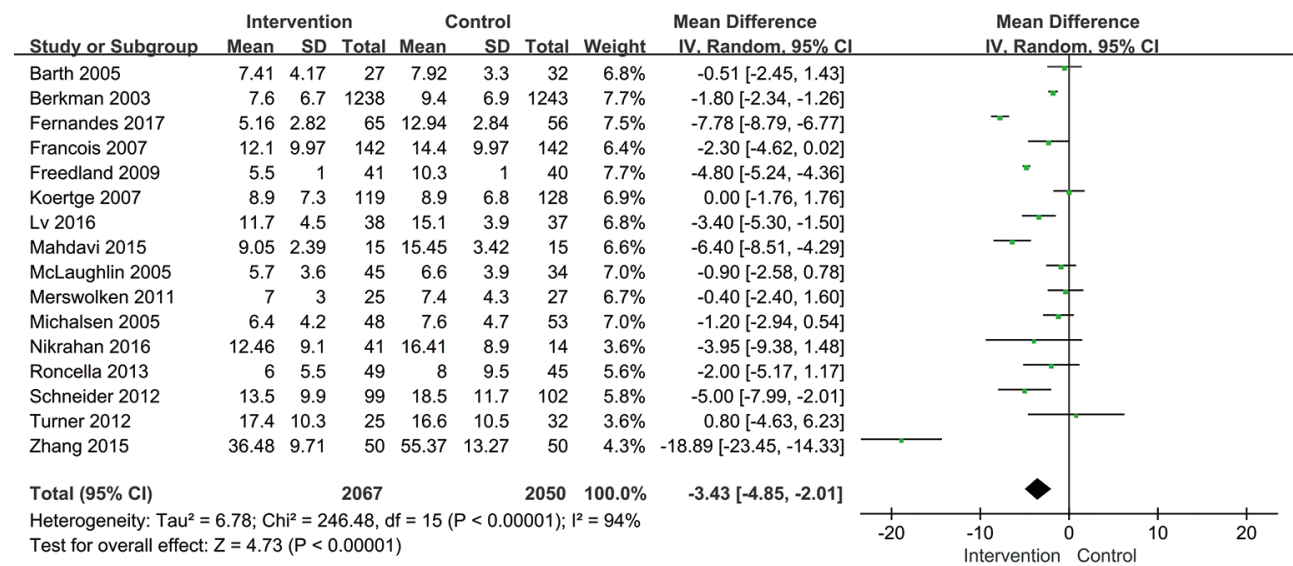

Figure 5 Forest plot showing the mean difference of depression scores between psychological intervention versus usual care.

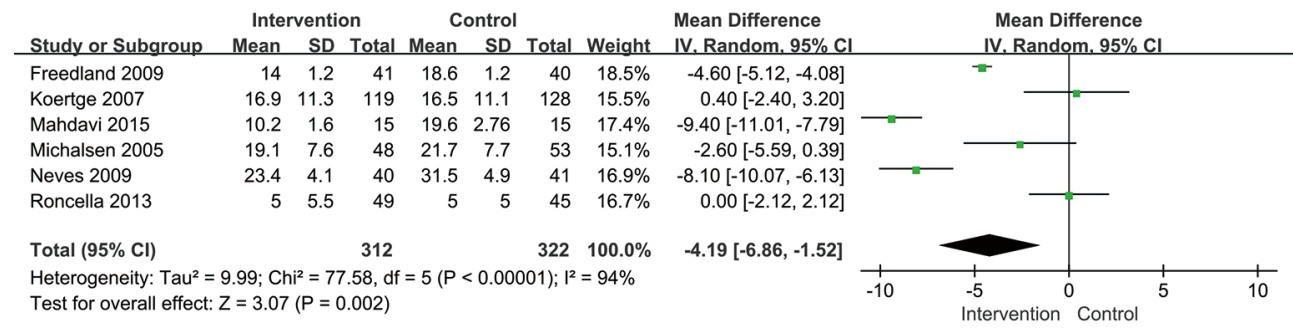

Figure 6 Forest plot showing the mean difference of stress scores between psychological intervention versus usual care.

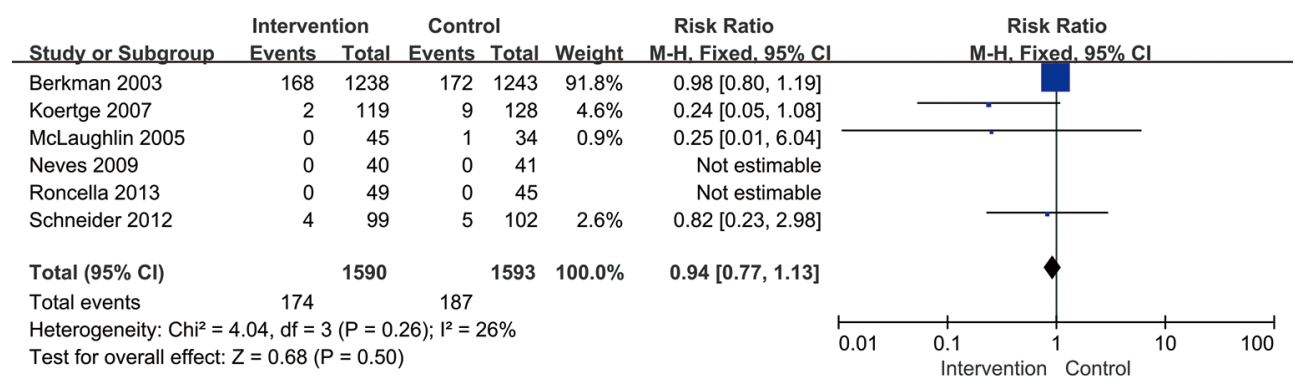

Figure 7 Forest plot showing the risk ratio of total mortality between psychological intervention versus usual care.

the intervention group and the control group, 6 articles involving 634 patients were included. Meta-analysis showed that compared to the control group, the intervention group had a lower level of stress (MD $=-4.19 ; 95 \% \mathrm{CI},-6.86$ to $-1.52 ; \mathrm{P}=0.002$, random effects model), with significant heterogeneity $\left(\mathrm{P}<0.00001 ; \mathrm{I}^{2}=94 \%\right.$; Figure 6).

A total of 6 studies reported the rate of total mortality. The forest plot showed no significant differences between the intervention group and the control group (RR 0.94; $95 \%$ CI, 0.77-1.13; $\mathrm{P}=0.50$, fixed effects model) and no significant heterogeneity among studies $\left(\mathrm{P}=0.26 ; \mathrm{I}^{2}=26 \%\right.$; Figure 7).

\section{Results of sensitivity analysis and publication bias}

A sensitivity analysis was carried out to evaluate the stability of the outcomes. The results of excluding a relative outlier showed that, for heterogeneity, $\mathrm{I}^{2}$ for anxiety changed from $96 \%$ to $93 \%$ when the 2017 Fernandes study was removed $(\mathrm{P}=0.001), \mathrm{I}^{2}$ for depression changed from $94 \%$ to $92 \%$ 
when the 2003 Berkman study was removed $(\mathrm{P}<0.001)$, and $\mathrm{I}^{2}$ for stress changed from $94 \%$ to $91 \%$ when the 2105 Mahdavi study was removed ( $\mathrm{P}=0.02)$. These results were not changed after sensitivity analysis, which indicated that the heterogeneity of these studies was relatively stable.

A funnel plot was performed to qualitatively evaluate the publication bias for 4 indexes. While the shape of the funnel plot showed some evidence of asymmetry, the Egger test was nonsignificant (anxiety $\mathrm{P}=0.72$, depression $\mathrm{P}=0.79$, stress $\mathrm{P}=0.45$, total mortality $\mathrm{P}=0.28)$.

\section{Discussion}

The rehabilitation of the heart requires multifaceted intervention, and aims to improve the health and quality of life for patients with coronary heart disease. The rehabilitation of the heart includes 3 core modes: education, exercise training, and psychological support $(33,34)$. Related studies have proved that anxiety and depression are important factors that contribute to coronary heart disease $(35,36)$. Under the influence of negative emotions such as anxiety, depression, and tension, the body's sympathetic excitability increases. This leads to increased adrenaline and adrenocortical hormone secretion, an accelerated heart rate, and even the inducement of arrhythmia (37). An excessive release of norepinephrine leads to vasoconstriction, increased blood pressure, increased myocardial oxygen consumption, angina pectoris, and even myocardial infarction (38).

With the transformation from a "biomedical model" to a "biological-psychological-social-medical model", it has been discovered that the occurrence of cardiovascular disease is closely related to psychosocial factors. Thus, the application of psychological intervention is an important measure in improving the quality of medical care. This is especially true for elderly patients who often have negative emotions, such as pessimism. Appropriate psychological intervention can achieve good results for those who are lonely with no dependence, and those with other basic diseases (39). Oranta's study evaluated the interpersonal counselling (IPC) implemented by a registered nurse on outcomes for depressive symptoms and distress in myocardial infarction patients. The results showed that in the IPC intervention group, depressive symptoms decreased from $37.3 \%$ to $20.4 \%$ at 6 months, and to $16.7 \%$ at 18 months, while distress decreased from $37.3 \%$ to $26.5 \%$ during the 6-month follow-up, and to $20.8 \%$ at 18 months (40).

A systematic review on the evaluation of clinical outcomes (such as death from myocardial infarction and heart failure) showed that there was a significant correlation between anxiety and health indicators of patients with heart disease in 5 studies, mild correlation in 3 studies, and no correlation in 4 studies (41). Roest et al. studied the relationship between anxiety and risk factors of coronary artery disease in a metaanalysis and found that anxiety was an independent risk factor of coronary heart disease and cardiac death (42). However, the association between anxiety and coronary heart disease was slightly lower than that found between depression and coronary heart disease, but this association was stronger than that found between irritable personality and coronary heart disease $(4,43)$. A survey on the physiological and psychological symptoms of patients with anxiety disorder and coronary heart disease showed that anxiety was related to physical factors. Patients with anxiety disorder can have palpitations, facial anger and redness, abnormal heartbeat, muscle tension, and other physical symptoms when not performing any physical activity, increasing the risk of coronary heart disease (44). It has been suggested that positive psychological intervention may play an important role in the treatment of heart disease with anxiety (45). However, due to the differences in social and cultural background, the effect of positive psychological intervention varies across different countries or regions $(46,47)$.

This study showed that compared with usual care, psychological intervention on patients with coronary heart disease can significantly improve patients' anxiety $(\mathrm{P}<0.00001)$, depression $(\mathrm{P}<0.00001)$, and stress scores $(\mathrm{P}=0.002)$. Although there was no strong evidence that psychological intervention can reduce total mortality in patients with coronary heart disease $(\mathrm{P}=0.50)$, a decrease in cardiac death $(\mathrm{RR}=0.94)$ in patients receiving intervention was observed. While this is not statistically significant, it may still have clinical importance. Specifically, scientific and rationally based psychological intervention can help patients with coronary heart disease have a positive and optimistic mood. This makes the endocrine system, autonomic nervous system, and immune system function optimally, enhancing the disease resistance ability of patients.

A number of limitations must be acknowledged here. The details of the intervention group and the control group were not well reported, which made it difficult to classify and compare the psychological intervention investigated in different studies. Researchers should pay more attention to the report of the test results and the description of the interventions provided. When the information is insufficient, the scalability and implementation of the positive results are affected. In addition, due to the lack of 
results of psychological intervention on clinical efficacy, the meta-analysis did not examine the efficacy of psychological intervention on clinical results, which will be an important objective of future analysis.

In conclusion, psychological intervention has important health benefits for patients with coronary heart disease and can effectively reduce negative psychological effects such as depression, anxiety, and stress. However, due to the influence of bias and limitations, large-sample and multicenter randomized control trials are still needed in the future. Researchers must provide clearer reports on their methods and interventions. Moreover, further analysis of this subject using more or different research indicators should be carried out to verify the conclusions.

\section{Acknowledgments}

Funding: None.

\section{Footnote}

Reporting Checklist: The authors have completed the PRISMA reporting checklist. Available at https://dx.doi. org/10.21037/apm-21-1623

Conflicts of Interest: All authors have completed the ICMJE uniform disclosure form (available at https://dx.doi. org/10.21037/apm-21-1623). The authors have no conflicts of interest to declare.

Ethical Statement: The authors are accountable for all aspects of the work in ensuring that questions related to the accuracy or integrity of any part of the work are appropriately investigated and resolved.

Open Access Statement: This is an Open Access article distributed in accordance with the Creative Commons Attribution-NonCommercial-NoDerivs 4.0 International License (CC BY-NC-ND 4.0), which permits the noncommercial replication and distribution of the article with the strict proviso that no changes or edits are made and the original work is properly cited (including links to both the formal publication through the relevant DOI and the license). See: https://creativecommons.org/licenses/by-nc-nd/4.0/.

\section{References}

1. Orth-Gomér K. Behavioral interventions for coronary heart disease patients. Biopsychosoc Med 2012;6:5

2. Peterson C, Kim ES. Psychological interventions and coronary heart disease. Int J Clin Health Psychol 2011;11:563-75.

3. Strodl E, Kenardy J. A history of heart interventions moderates the relationship between psychological variables and the presence of chest pain in older women with selfreported coronary heart disease. Br J Health Psychol 2013;18:687-706.

4. Richards SH, Anderson L, Jenkinson CE, et al. Psychological interventions for coronary heart disease. Cochrane Database Syst Rev 2017;4:CD002902.

5. Chan I, Lai J, Wong K. Resilience is associated with better recovery in Chinese people diagnosed with coronary heart disease. Psychol Health 2006;21:335-49.

6. Valiee S, Razavi NS, Aghajani M, et al. Effectiveness of a psychoeducation program on the quality of life in patients with coronary heart disease: A clinical trial. Appl Nurs Res 2017;33:36-41.

7. Whalley B, Thompson DR, Taylor RS. Psychological interventions for coronary heart disease: cochrane systematic review and meta-analysis. Int J Behav Med 2014;21:109-21.

8. Rahimian-Boogar I, Rostami R. Health Related Quality of Life in Patients with Coronary Heart Disease: Psychological and Socio-Demographical Determinants. J Res Med Sci 2014;16.

9. Friedman HS, Booth-Kewley S. The "disease-prone personality". A meta-analytic view of the construct. Am Psychol 1987;42:539-55.

10. Menninger KA. Residencies in Neuropsychiatry. KA Menninger (1937). Reprinted from the J Nerv Ment Dis. 86(2): 245. J Nerv Ment Dis 2012;200:189.

11. ROSENMAN RH, FRIEDMAN M, STRAUS R, et al. A PREDICTIVE STUDY OF CORONARY HEART DISEASE. JAMA 1964;189:15-22.

12. Huffman JC, Millstein RA, Mastromauro CA, et al. A Positive Psychology Intervention for Patients with an Acute Coronary Syndrome: Treatment Development and Proofof-Concept Trial. J Happiness Stud 2016;17:1985-2006.

13. Sanjuán P, Montalbetti T, Pérez-García AM, et al. A Randomised Trial of a Positive Intervention to Promote Well-Being in Cardiac Patients. Appl Psychol Health Well Being 2016;8:64-84.

14. Rakowska JM. Brief strategic therapy in first myocardial infarction patients with increased levels of stress: a randomized clinical trial. Anxiety Stress Coping 2015;28:687-705. 
15. Salminen M, Isoaho R, Vahlberg T, et al. Effects of a health advocacy, counselling, and activation programme on depressive symptoms in older coronary heart disease patients. Int J Geriatr Psychiatry 2005;20:552-8.

16. Fernandes AC, McIntyre T, Coelho R, et al. Brief psychological intervention in phase I of cardiac rehabilitation after acute coronary syndrome. Rev Port Cardiol 2017;36:641-9.

17. Aghaei M, Samkhaniyan E, Mahdavi A, et al. Effectiveness of behavioral-cognitive group therapy on depression, anxiety, and stress of patients with coronary heart disease. J Med Life 2015;8:252-7.

18. Berkman LF, Blumenthal J, Burg M, et al. Effects of treating depression and low perceived social support on clinical events after myocardial infarction: the Enhancing Recovery in Coronary Heart Disease Patients (ENRICHD) Randomized Trial. JAMA 2003;289:3106-16.

19. McLaughlin TJ, Aupont O, Bambauer KZ, et al. Improving psychologic adjustment to chronic illness in cardiac patients. The role of depression and anxiety. J Gen Intern Med 2005;20:1084-90.

20. Lv J, Zhang X, Ou S, et al. Influence of Cognitive Behavioral Therapy on Mood and Quality of Life After Stent Implantation in Young and Middle-Aged Patients With Coronary Heart Disease. Int Heart J 2016;57:167-72.

21. Barth J, Paul J, Härter M, et al. Inpatient psychotherapeutic treatment for cardiac patients with depression in Germany - short term results. Psychosoc Med 2005;2:Doc04.

22. Roncella A, Pristipino C, Cianfrocca C, et al. Oneyear results of the randomized, controlled, short-term psychotherapy in acute myocardial infarction (STEP-INAMI) trial. Int J Cardiol 2013;170:132-9.

23. Michalsen A, Grossman P, Lehmann N, et al. Psychological and quality-of-life outcomes from a comprehensive stress reduction and lifestyle program in patients with coronary artery disease: results of a randomized trial. Psychother Psychosom 2005;74:344-52.

24. Turner A, Hambridge J, Baker A, et al. Randomised controlled trial of group cognitive behaviour therapy versus brief intervention for depression in cardiac patients. Aust N Z J Psychiatry 2013;47:235-43.

25. Schneider RH, Grim CE, Rainforth MV, et al. Stress reduction in the secondary prevention of cardiovascular disease: randomized, controlled trial of transcendental meditation and health education in Blacks. Circ Cardiovasc Qual Outcomes 2012;5:750-8.

26. Zhang P. Study of Anxiety/Depression in Patients with
Coronary Heart Disease After Percutaneous Coronary Intervention. Cell Biochem Biophys 2015;72:503-7.

27. Neves A, Alves AJ, Ribeiro F, et al. The effect of cardiac rehabilitation with relaxation therapy on psychological, hemodynamic, and hospital admission outcome variables. J Cardiopulm Rehabil Prev 2009;29:304-9.

28. Merswolken M, Siebenhuener S, Orth-Gomér K, et al. Treating anxiety in patients with coronary heart disease: a randomized controlled trial. Psychother Psychosom 2011;80:365-70.

29. Freedland KE, Skala JA, Carney RM, et al. Treatment of depression after coronary artery bypass surgery: a randomized controlled trial. Arch Gen Psychiatry 2009;66:387-96.

30. Nikrahan GR, Suarez L, Asgari K, et al. Positive Psychology Interventions for Patients With Heart Disease: A Preliminary Randomized Trial. Psychosomatics 2016;57:348-58.

31. Francois L, Nancy FS, Diana K, et al. Effects of Citalopram and Interpersonal Psychotherapy on Depression in Patients With Coronary Artery Disease. JAMA 2007;3:12-7.

32. Koertge J, Janszky I, Sundin O, et al. Effects of a stress management program on vital exhaustion and depression in women with coronary heart disease: a randomized controlled intervention study. J Intern Med 2008;263:281-93.

33. Allan R, Scheidt SS. Heart \& mind: The practice of cardiac psychology. Am Psychol Assoc 2011;20:335-42.

34. Biering K, Hjøllund NH, Lund T. Methods in measuring return to work: a comparison of measures of return to work following treatment of coronary heart disease. J Occup Rehabil 2013;23:400-5.

35. Nehra DK, Sharma KL, Kumar RR. Efficacy of MBSR Program in Treating Depression, Anxiety and Perceived Stress in Coronary Heart Disease Patients. India J Positive Psychol 2012;24:65-71.

36. Kop WJ. Depression and coronary heart disease: Diagnosis, predictive value, biobehavioral mechanisms, and intervention. Heart Mind (Mumbai) 2011;17:89-94.

37. ENRICHD Investigators. Enhancing Recovery in Coronary Heart Disease (ENRICHD) study intervention: rationale and design. Psychosom Med 2001;63:747-55.

38. Tully PJ, Baumeister H. Collaborative care for the treatment of comorbid depression and coronary heart disease: a systematic review and meta-analysis protocol. Syst Rev 2014;3:127.

39. Koerselman GF. How to guard the interconnection of 
biological, psychological and social factors in psychiatry? Psychosom Med 2000;37:75-8.

40. Oranta O, Luutonen S, Salokangas RK, et al. The outcomes of interpersonal counselling on depressive symptoms and distress after myocardial infarction. Nord J Psychiatry 2010;64:78-86.

41. Grace SL, Abbey SE, Irvine J, et al. Prospective examination of anxiety persistence and its relationship to cardiac symptoms and recurrent cardiac events. Psychother Psychosom 2004;73:344-52.

42. Roest AM, Martens EJ, de Jonge P, et al. Anxiety and risk of incident coronary heart disease: a meta-analysis. J Am Coll Cardiol 2010;56:38-46.

43. Lau-Walker MO, Cowie MR, Roughton M. Coronary heart disease patients' perception of their symptoms and sense of control are associated with their quality of life three years following hospital discharge. J Clin Nurs 2009; 18:63-71.

Cite this article as: Zhang Y, Liang Y, Huang H, Xu Y. Systematic review and meta-analysis of psychological intervention on patients with coronary heart disease. Ann Palliat Med 2021;10(8):8848-8857. doi: 10.21037/apm-21-1623
44. Ladwig KH, Marten-Mittag B, Baumert J, et al. Psychosocial factors as risk for coronary heart disease-status with special reference to the KORA platform. Gesundheitswesen 2005;67 Suppl 1:S86-93.

45. Barth J, Jacob T, Daha I, et al. Psychosocial interventions for smoking cessation in patients with coronary heart disease. Cochrane Database Syst Rev 2015;(7):CD006886.

46. Pischke CR, Scherwitz L, Weidner G, et al. Long-term effects of lifestyle changes on well-being and cardiac variables among coronary heart disease patients. Health Psychol 2008;27:584-92.

47. Sanjuán P, Arranz H, Castro A. Effect of negative attributions on depressive symptoms of patients with coronary heart disease after controlling for physical functional impairment. Br J Health Psychol 2014;19:380-92.

(English Language Editors: D. Estela and J. Gray) 